\title{
Reflexões sobre a educação escolar quilombola: elementos para a prática docente
}

\author{
Evanilson Tavares de França* \\ Maria Batista Lima**
}

\begin{abstract}
Resumo
A compreensão de quilombo como território de resistência e preservação da cultura de base africana perpassa os discursos de pesquisadores diversos, como Almeida, O’Dwyer e Arruti, inserindo-se nas análises deste último as ressemantizações sofridas pelo termo e os determinantes históricos que as trouxeram à luz. A ressemantização, ainda segundo Arruti, que interpreta quilombo como território de resistência, vai compor as bandeiras do Movimento Negro Unificado (MNU). Por outro lado, o entendimento de currículo como relação de poder e como instrumento/estratégia capaz de interferir na formação do outro revela o quanto este instituto pedagógico é capaz de inserir/excluir, empoderar/fragilizar, desvelar/camuflar. É neste cenário de entendimentos que se insere este artigo, objetivando pensar/propor saberes capazes de fomentar a Educação Escolar Quilombola nos territórios dos remanescentes quilombos e nas unidades de ensino que atendem a estudantes originários/as daquelas comunidades. Para tanto, construímos diálogos com as legislações (vigentes) e com teóricos que abordam a temática.

Palavras-chave: quilombo; currículo; educação escolar quilombola.
\end{abstract}

\section{Reflections on quilombola school education: elements for teaching practice}

\begin{abstract}
The understanding of a quilombo as a resistance territory and african culture preservation territory permeates the words of several researchers, such as Almeida, O'Dwyer and Arruti, being inserted in the last author's analysis the changes in meaning suffered by the expression and the historical determinants which brought those to light. - It's precisely the change in meaning, still according to Arruti, who interprets a quilombo as a space/time of resistance that will compose the flags of the United Black Movement (UBM). On the other hand, the understanding of curriculum as a power relation and as a tool/strategy capable of interfering in the formation of other emphasizes how much this pedagogic institute is able to insert/exclude, empower/weaken, revealing/hiding. It is in such a scenario of thoughts and understandings that this article is inserted, aiming to think/propose knowledges capable of promoting Quilombola School Education in the territories of the remaining quilombos and at the educational units that assist students originated/from that community. To do so, we have established dialogues with legislations (in effect) and also with theorists who do research on the topic.
\end{abstract}

Keywords: quilombo; curriculum; quilombola school education.

\section{Palavras iniciais}

As leis $10.639 / 2003^{1}$ e $11.645 / 2008^{2}$, assim como da Resolução CNE/CP N. ${ }^{\circ} 01 / 2004^{3}$ e a Resolução CNE/CEB N. ${ }^{\circ}$ 08/2012resultam de lutas históricas travadas pelo povo negro, as quais, como enfatiza Domingues (2007, p. 33), sempre empunharam aguerridamente a bandeira da educação, buscando, inclusive, a "inclusão de conteúdos programáticos referentes à história da África e da cultura afro-brasileira nos currículos das escolas".

De cunho assistencialista, cultural e/ou recreativo (mas sempre de resistência), as agremiações, associações ou agrupamentos reuniam um número significativo de negros/as que buscavam empoderar suas reivindicações e/ou assegurar a manifestação da cultura de seus ascendentes, o que lhes assegurava pertencimento étnico, elementos para estruturação da identidade e um lugar, como sujeito, em um status quo gerador de exclusão. Simultaneamente às agremiações e associações, surge a chamada imprensa negra, "jornais publicados por negros e elaborados para tratar de suas questões" (DOMINGUES, 2007, p. 107).

Na década de 70, do século XX, exatamente em 1978, coroando as longas lutas de homens e mulheres negros/as (e de não-negros/as defensores/as de uma sociedade justa e inclusiva) nasce o Movimento Unificado Contra a Discriminação Racial. Em 1979 acontece o primeiro congresso organizado por este movimento. E é exatamente neste evento que o movimento passa a se denominar Movimento Negro Unificado (MNU), objetivando a unificação das lutas contra o racismo no Brasil. Gonçalves e Silva (2000) afirmam que

*Professor e pedagogo da Rede Estadual de Ensino - Sergipe (SEED/SE). Endereço eletrônico: evanilsont@ gmail.com

**Professora da Universidade Federal de Sergipe (UFS). Endereço eletrônico: mabalima.ufs@ gmail.com 
dentre as bandeiras de luta hasteadas pelo MNU destaca-se a da educação. Munanga (2005, p. 54) reforça que o Movimento Negro "[...] sempre reivindicou políticas específicas que pudessem reduzir as desigualdades e colocar o negro em pé de igualdade com o branco" - e a Educação ilustrou essas políticas.

A Constituição Federal de 1988 é outro marco digno de registro no que tange à convergência das conquistas sociais alcançadas pelos movimentos sindicais e sociais brasileiros. Com o fim da ditadura militar e a euforia irrestrita, convergida no Movimento Diretas Já, estudantes, negros/as, mulheres, gays e outros movimentos sociais vislumbram a possibilidade de ressignificação do Estado brasileiro e de implementação de novas relações sociais, pautadas no respeito, na solidariedade e na igualdade entre os homens (e as mulheres).

Como consequência dessas perspectivas, e com aquiescência de um Estado que se propõe democrático, nasce a Lei 10.639/2003. O artigo 26 A deste instrumento institui que "nos estabelecimentos de ensino fundamental e médio, oficiais e particulares, torna-se obrigatório o ensino sobre História e Cultura Afro-Brasileira" (BRASIL, 2003), alterando a LDB 9394/96.

A criação da Secretaria Especial de Políticas de Promoção da Igualdade Racial (SEPPIR) e a adoção de políticas específicas para a construção de um pensamento nacional voltado para o respeito à diversidade foram outras estratégias implementadas pelo governo que fortaleceram as lutas do povo negro e asseguraram algumas reinvindicações.

Mais um passo em direção à construção de uma escola pública inclusiva é dado em 2004 a partir da publicação das Diretrizes Curriculares Nacionais para Educação das Relações Étnicoraciais e para o Ensino de História e Cultura Afrobrasileira e Africana. Este instrumento é bastante significativo porque estabelece uma série de procedimentos e atitudes em direção ao reconhecimento dos valores culturais africanos e afro-brasileiros e aponta para um currículo onde o/a negro/a se veja representado/a - contribuindo, desta forma, para ressignificação das relações étnicoraciais dentro e fora da escola. Essa Resolução, assim como ocorre com a Lei 10.639/2003, se sobressai também por trazer à luz o reconhecimento oficial dos preconceitos, das discriminações e do racismo brasileiro.

Contudo, o instrumento que em nossa ótica inicia uma proposta para educação quilombola somente se corporifica em 2010, a partir do Parecer CNE/CEB 07/2010, aprovado em 07 de abril daquele mesmo ano. Esse documento assevera que "a Educação Escolar Quilombola é desenvolvida em unidades educacionais inscritas em suas terras e cultura, requerendo pedagogia própria em respeito à especificidade étnico-cultural de cada comunidade e formação especifica de seu quadro docente [...]". (BRASIL, 2010, p. 42).

Antes de nos imiscuirmos na Educação Escolar Quilombola, consideramos indispensável percorrermos, ainda que em breves linhas, o roteiro traçado pela construção da definição de quilombo; mesmo porque aquela modalidade de educação engloba, como estabelece a Resolução CNE/CEB N. ${ }^{\circ}$ 08/2012, "I - escolas quilombolas; II - escolas que atendem estudantes oriundos de territórios quilombolas" (BRASIL, 2012, Art. $9^{\circ}$ ).

Segundo Almeida (2002), resgatando a definição construída a partir de consulta feita pelo rei de Portugal ao Conselho Ultramarino, em 1740, o conceito de quilombo abarcava necessariamente: fuga de escravos; quantidade mínima de escravizados ocupando o mesmo espaço, ao mesmo tempo; localização do espaço ocupado, que deveria situar-se em região geográfica de difícil acesso, marcada pelo isolamento. Acrescentava ainda a existência de moradia fixa (os ranchos) e de pilões, com os quais os/as negros/as poderiam beneficiar o arroz, alimento que simbolizava o autoconsumo e a capacidade de reprodução - estes dois últimos elementos presentesna definição não eram, contudo, imprescindíveis para compô-la.

Arruti (2008) acrescenta que, enquanto na legislação colonial para a existência de um quilombo era necessáriaa presença de cinco escravos fugidos, ocupando ranhos permanentes, na legislação imperial bastava a reunião de três escravos evadidos, mesmo que não formassem ranchos permanentes. E adiciona: "Neste contexto, afirmar a existência de um quilombo significava apenas identificar um objeto de repressão, sem que isso necessitasse ou implicasse qualquer conhecimento objetivo sobre tal objeto" (ARRUTI, 2008 , p. 04). Como se observa, a definição do termo (quilombo) encontrava-se potencialmente imbricada pelos interesses em jogo e pelo desejo de reprimir o povo negro, conforme evidencia França (2013).

Mesmo preservando certo alinhamento ideológico, os sentidos atribuídos a quilombo sofrem ligeira alteração na passagem do Brasil Colônia para o Brasil Império. Já durante a república, ainda seguindo a trilha de Arruti (2008), é 
perceptível certa ruptura com as concepções precedentes. Nesse período, as ressemantizações abrangiam desde o entendimento de quilombo como espaço de resistência cultural, quando Nina Rodrigues, em conformidade com Arruti (2008), afirma tratar-se de um retorno à barbárie africana, passando pelo sentido de resistência política e chegando ao entendimento de resistência negra.

No que concerne à primeira acepção (quilombo enquanto espaço de resistência cultural), Arruti lembra que esta ressemantização é posta em prática, desde 1905, quando Nina Rodrigues, pela primeira vez, caracterizou Palmares como "uma forma de persistência da África no Brasil" (ARRUTI, 2008, p. 05). Já a ressemantização que compreende quilombo como espaço de resistência política, seguindo Arruti (2008, p. 05), a "referência à África é substituída pela referência ao Estado ou às estruturas de dominação de classe e o quilombo (em especial Palmares) serve para pensar as formas potencialmente revolucionárias de resistência popular” (ARRUTI, 2008, p. 05). A ressemantização que atribui aos quilombos o sentido de resistência negra é um construto, consoante Arruti, do Movimento Negro, o qual, "somando a perspectiva cultural ou racial à perspectiva política, elege o quilombo como ícone da 'resistência negra"" (2008, p. 06).

Ainda que o binômio fuga-resistência mobilize as concepções de quilombo, consideramos importante trazer à baila, apoiando-nos em Schmitt, Turatti e Manzoli (2002, p. 03), que nem sempre aqueles espaços foram constituídos por negros e negras que escaparam das fazendas e engenhos ou foram palcos de confrontos entre africanos/as e seus/suas descendentes e os escravagistas e os seus comandados: "As heranças, doações, recebimento de terras como pagamento de serviços prestados ao Estado, a simples permanência nas terras que ocupavam e cultivavam no interior das grandes propriedades, bem como a compra de terras, tanto durante a vigência do sistema escravocrata quanto após a sua extinção" representaram outras modalidades de formação de quilombos.

Presentes em todas as regiões onde a escravização dos/as africanos/asse converteu em política oficial, os quilombos, palavra oriunda de kilombo, termo de origem banto que, originariamente, representavam "um agrupamento militar composto dos jagas ou imbangas (de Angola) e dos lundas (do Zaire) no século XVII" (BRASIL, 2013, p. 428), no Brasil estes agrupamentos ganharam conotações próprias e foram se firmando a partir de estratégias singulares. Contudo, independentemente dos modos de aquilombamento, é correto afirmar que em todos eles a reação ao sistema escravocrata e a inspiração em África são pontos fulcrais, o que lega a essas comunidades peculiaridades próprias.

A abordagem de quilombos como "grupos culturalmente diferenciados", constante no Decreto 6040/2007 e presente na Política Nacional de Desenvolvimento Sustentável dos Povos Tradicionais e alinhado com a Convenção 169 da Organização Internacional do Trabalho (OIT), harmoniza-se com as concepções contemporâneas de quilombo e com outros textos legais que abordam a temática, a exemplo do Decreto N. ${ }^{\circ}$ $4.887 / 2003$, que regulamenta o procedimento para identificação, reconhecimento, delimitação, demarcação e titulação das terras ocupadas por remanescentes das comunidades dos quilombos, e que os define como "grupos étnico-raciais, segundo critérios de auto-atribuição, com trajetória histórica própria, dotados de relações territoriais específicas, com presunção de ancestralidade negra relacionada com a resistência à opressão histórica sofrida" (BRASIL, 2003, Art. $2^{\circ}$ ).

Para o Programa Brasil Quilombola (PBQ), coordenado pela Secretaria Especial de Promoção de Política de Igualdade Racial (SEPPIR), "as comunidades quilombolas se caracterizam pela prática do sistema de uso comum de suas terras, concebidos por elas como um espaço coletivo e indivisível que é ocupado e explorado por meio de regras consensuais aos diversos grupos familiares que compõem as comunidades" (BRASIL, 2004, p. 11).

De acordo com O’Dwyer (2002), o conceito de quilombo na contemporaneidade recebe nova semantização, desta feita não se restringindo a espaços "constituídos a partir de movimentos insurrecionais ou rebelados, mas, sobretudo, consistem em grupos que desenvolveram práticas cotidianas de resistência na manutenção e reprodução de seus modos de vida característicos e na consolidação de um território próprio". (O'DWYER, 2002, p. 19).

Em nosso entendimento, compreender os dispositivos ideológicos que gestam teorias e, consequentemente, conceitos e definições que as subjazem, assim como re/conhecer os processos históricos dos povos e comunidades, com grifo naqueles que foram alvos de exploração e vítima do terror original, citando expressão cara a Gilroy (2012), como ocorreu com os/as africanos/as e seus 
descendentes, é fundamental para planejamento e concretização de qualquer política pública, principalmente aquelas que tenham como objetivo a reparação dos processos históricos de agrilhoamento e marginalização dos povos e o seu empoderamento social e cultural.

\section{Uma educação para os remanescentes de quilombos}

\section{A educação e seus desdobramentos}

Iniciaremos estas discussões efetuando uma ligeira, mas fundamental reflexão sobre educação no seu sentido mais lato e, logo após, percorreremos alguns passos pela educação oferecida nas salas de aula - e que é necessariamente aquela a que se refere à Resolução CNE/CEB N. ${ }^{\circ}$ 08/2003.

Concordamos com Libâneo (1994, p. 16) quando este autor compreende educação como fenômeno universal e atributo humano necessário à "existência e funcionamento de todas as sociedades". E assim o é porque cada sociedade precisa adotar critérios e estratégias para a educação dos sujeitos que a compõem. É através e pela educação que os conhecimentos produzidos ganham contornos e atravessam as gerações, podendo, inclusive, ser ampliados ou refutados - de qualquer sorte, será sempre uma tese que dará origem a uma antítese que poderá ou não se transformar em nova tese, aguardando nova refutação.

É também pela educação que a cultura atravessa as gerações e, mesmo que as identidades coletivas se encontrem em crise, como questiona Hall (2006), os modos de fazer cultura e as marcas que ela impinge nos indivíduos atribuem a estes, propriedades peculiares que interferem em suas formas de ver, de fazer, de se relacionar e de compreender o mundo no qual vão tecendo sua existência. A cultura é inquestionavelmente conteúdo educacional, ainda que a relação entre ambas, educação e cultura, promova a transformação das duas.

A educação, de forma ampliada, compreende, portanto, "os processos formativos que ocorrem no meio social, nos quais os indivíduos estão envolvidos do modo necessário e inevitável pelo simples fato de existirem socialmente. (LIBÂNEO, 1994, p. 17, grifos do autor). No seu sentido estrito, a educação se efetua em instituições específicas, criadas para atender a determinados objetivos. Para tanto, há uma planificação intencional: definem-se os conteúdos que comporão o currículo, o tipo de cidadão que se pretende formar, os valores que mobilizarão as ações da escola e até mesmo o tipo de profissional que se deseja.

Ainda que, neste último caso, não se possa falar em relação biunívoca, ou seja, o cidadão que se busca formar muito provavelmente não será fotocópia do pretendido, a intenção que sustenta programas e projetos, em muitas situações, é que o seja. Nidelcoff (1985, p. 15) assegura que "a escola se limita a reproduzir no seu interior a desigualdade de oportunidades que caracteriza a estrutura de nossa sociedade", mas esta mesma autora acrescenta que "a escola que o povo recebe é muito mais a escola que os professores organizam com sua maneira de ser, de falar e de trabalhar, do que a escola criada pelos organismos ministeriais e pelos textos escolares" (ibidem, p. 17, grifos da autora).

Finalmente, é também a escola que se converte em palco cotidiano de encontros e desencontros, de confrontos e negociações. E nela, mesmo que os currículos oficiais, representados pelos programas e projetos e também pelos livros didáticos, visem à configuração de um tipo determinado de escola e de sujeito, os atores sociais, que tornam os estabelecimentos de ensino uma realidade, interferem consciente ou inconscientemente na efetivação das propostas curriculares, porque, como declara Macedo (2013), somos todos sujeitos curriculantes.

\section{Currículo: limites e desafios}

Talvez, o melhor modo de promover reflexões/discussões sobre currículo seja a partir da tentativa de abordá-lo como território em disputa (SILVA, 2003). E isso nos parece bastante apropriado porque, como nos ensina Santos (2009), o espaço territorial é o lócus do exercício de Poder. E currículo é o espaço/tempo onde os interesses ideológicos reivindicam propriedade, hegemonia. E este confronto de forças encontra na escola ambiente profícuo. E não deve ser diferente - não há como ser diferente. Torna-se, contudo, imprescindível que este entendimento engravide (no sentido freireano) reflexões e ações de todos os sujeitos que tornam a escolaum lugar vivo e viável.

O currículo é também um objeto cultural, o que o torna imensamente presente (e significativo) no processo de construção identitária dos sujeitos. Contudo, precisamos retornar à questão de território em disputa, que a todo momento alinhavará qualquer reflexão sobre currículo. No exercício desta função (enquanto objeto cultural) se efetiva um evidente e doloroso processo de seleção cultural 
escolar que, como define Forquin, "é sempre o resultado de um compromisso instável entre exigências divergentes, interesses contraditórios, ideologias opostas, e nada do que figura nos programas pode pretender jamais uma justificação completamente racional" (FORQUIN, 1993, p. 140).

Neste processo de seleção cultural, selecionam-se também os valores e sua viabilidade na formação do sujeito. Ou seja, o que não é valorizado pela escola precisa ser negado pelos/as estudantes se quiserem ter sucesso na escola e na vida. Este comportamento curricular produz certa traição: os/as alunos/as oriundos/as das camadas populares ou de comunidades tradicionais, cujo prestígio social e cultural degringolou-se (ou se encontra em processo de) na escola, devem negar suas origens e seus valores culturais. E negando-os, nega suas famílias e negam-se a si mesmos/as - é a concretização do lastimável fenômeno apresentado por Charlot (2005): aprender é trair.

Currículo é ainda uma construção social. Portanto, tratá-lo "como algo dado ou uma realidade objetiva e não como um processo no qual podemos realizar cortes transversais e ver como está configurado num dado momento não seria mais que legitimar de antemão a opção estabelecida nos currículos vigentes, fixando-a como indiscutível" (SACRISTÁN, 1998, p. 16). Consideramos importante acrescentar que tal postura, ao assegurar a manutenção do status quo, fortalece as políticas sociais que historicamente empurram para as margens da sociedade os diferentes ou, com o intuito de construir uma fisionomia falsamente democrática, propalam uma política de diversidade que insere todos numa mesma amálgama, o que contribui para anulação das diferenças que os constitui.

Acrescentamos ainda que o entendimento de currículo como instrumento/estratégia responsável por atribuir sentido aos objetos, aos fatos e fenômenos, por significar as relações e as pessoas que nelas atuam, por representar o mundo e a presença e pertencimento de homens e mulheres nele é essencial para que compreendamos como este objeto, o currículo, é capaz de empoderar ou marginalizar, develar ou desvelar.

Para Lopes e Macedo, "qualquer manifestação do currículo, qualquer episódio curricular, é a mesma coisa: a produção de sentidos. Seja escrito, falado, velado, o currículo é um texto que tenta direcionar o 'leitor', mas que o faz parcialmente" (LOPES; MACEDO, 2011, p. 41). E "o faz apenas parcialmente" porque os indivíduos que protagonizam a ação pedagógica são racionais, têm aspirações e por elas lutam, têm uma história e, mesmo que por ela não sejam determinados, sofrem condicionamentos que interferem em seus pensamentos e práticas, têm uma história cultural que lhes impinge percepções e contribuem para as representações de mundo que eles constroem.

\section{Para os remanescentes de quilombos uma Educação Escolar Quilombola}

A Educação Escolar Quilombola não figura na LDB 9394, promulgada em 20 de dezembro de 1996. Dentre as modalidades componentes daquele texto legal constam: Educação de Jovens e Adultos (EJA), Educação Especial, Educação Profissional, Educação Indígena, Educação do Campo e Ensino a Distância. Miranda lembra que "as modalidades referem-se [sic] às formas distintas que a estrutura $\mathrm{e}$ a organização do ensino adotarão para adequaremse às necessidades $\mathrm{e}$ às disponibilidades que garantam condições de acesso e permanência na escola" (MIRANDA, 2012, p. 366).

No momento de aprovação da nova LDB, como era chamada (e algumas vezes ainda o é), as necessidades das comunidades quilombolas e suas disponibilidades não foram tomadas em consideração. Isto se efetua, entretanto, com a Resolução CNE/CEB N. ${ }^{\circ}$ 07/2010, que fixa diretrizes curriculares nacionais para o Ensino Fundamental de 09 anos, estabelecendo que "a Educação Escolar Indígena e a Educação Escolar Quilombola são, respectivamente, oferecidas em unidades educacionais inscritas em suas terras e culturas e, para essas populações [...]" (BRASIL, 2010, Art. 39). Este é um preceito oriundo do Parecer CNE/CEB N. ${ }^{\circ}$ 07/2010, segundo o qual "a Educação Escolar Quilombola [deve ser] desenvolvida em unidades educacionais inscritas em suas terras e cultura, requerendo pedagogia própria em respeito à especificidade etnicocultural [sic] de cada comunidade e formação específica de seu quadro docente" (BRASIL, 2010, p. 42).

A Resolução CNE/CEB N. ${ }^{\circ}$ 08/2012, "que define Diretrizes Curriculares Nacionais para a Educação Escolar Quilombola na Educação Básica" (EMENTA), aprovada em 20 de novembro, amplia este atendimento estabelecendo que tanto as unidades de ensino situadas em comunidades quilombolas como aquelas que atendem estudantes originários de quilombos devem oferecer a Educação Escolar Quilombola (BRASIL, 2012, Art. $\left.9^{\circ}\right)$. 
Estes degraus duramente galgados, partindo de uma legislação que não reconhece a Educação Escolar Quilombola como uma necessidade (LDB 9394/96) e alcançando a aprovação de uma Resolução (CNE/CEB N. ${ }^{\circ}$ 08/2012), que define princípios, amplitude e responsabilidades, sãoefeitos das lutas e captações que encontram explicação na caminhada histórica do povo negro, quilombola ou não, e no entendimento visceral, deste mesmo povo, de que a educação formal é um instrumento essencial para que se assegure direitos e para que se possa acessar os bens simbólicos e materiais valorizados socialmente.

Aliás, "a promoção da história e cultura ressignificada, recriada e reterritorializada nos territórios quilombolas" é um dos elementos constitutivos da Resolução CNE/CEB N. ${ }^{\circ}$ 08/2012, prescrito no Artigo 35. Esse mesmo instrumento, no seu sétimo artigo, estabelece os princípios que devem reger as práticas e ações políticopedagógicas, compreendendo desde o "direito à igualdade, liberdade, diversidade e pluralidade (I)" e chegando ao "reconhecimento do lugar social, cultural, político, econômico, educativo e ecológico ocupado pelas mulheres no processo histórico de organização das comunidades quilombolas e construção de práticas educativas que visem à superação de todas as formas de violência racial e de gênero" (XX).

Estes princípios são referências indispensáveis à construção de uma educação que precisa edificar-se a partir do compromisso de emancipaçãodos sujeitos. E esta emancipação somente se efetua satisfatoriamente se o conhecimento e o reconhecimento da história e cultura de seus ancestrais converter-seem currículo escolar cotidiana e plenamente.

Brasil (2013) lembra que

Ao longo dos anos, juntamente com outros povos e comunidades considerados tradicionais e em articulação com outros movimentos sociais, os quilombos, por meio de suas ações e articulação política, têm contribuído no processo de mudança no próprio campo jurídico, na aplicação $e$ interpretação das leis, pressionando o Estado e o próprio Direito a realizar a devida relação entre os princípios da igualdade e da pluralidade (BRASIL, 2013, p. 433).

A história e cultura do povo negro e por consequência dos remanescentes de quilombodevem ser transportadas adequadamente para as salas de aula das escolas quilombolas - e também daquelas que não ofertam essa modalidade de ensino. E, se nos apoiarmos nas pesquisas de Cunha Júnior (2006, 2010), de Oliveira $(2011,2012)$ e Gerdes (1997, 2010a, 2010b) encontraremos elementos diversos e ricos para composição dos conteúdos programáticos de todas as disciplinas, incluindo aí a Matemática.

Cunha Júnior (2010), por exemplo, resgata uma série de produções africanas (muitas delas realizadas séculos antes do seu equivalente no continente europeu): as agriculturas conhecidas como tropicais foram desenvolvidas na África antes do século XVI: "culturas como cana-de-açúcar, banana, café, algodão, arroz e amendoim eram bastante desenvolvidas em regiões africanas" (p. 11); no século XVII, países como Congo e Kano exportavam tecido para a Europa; a cultura do gado e do couro, largamente utilizada no Brasil colônia e império, tem origem africana; a metalurgia brasileira, naquele mesmo período, encontrou nascedouro nos conhecimentos oriundos da África.

Esse mesmo autor reforça que o conhecimento da história da África e do povo africanos é fundamental para compreender o surgimento de várias técnicas e outros conhecimentos que aportaram no Brasil e que deram a este País as condições para que ele atravessasse o período colonial, o império e se transformasse numa república capaz de se apresentar no cenário mundial de forma digna.

A afroetnomatemática, ainda para Cunha Júnior (2006, p. 62), é uma "área da pesquisa que estuda os aportes de africanos e afrodescendentes à matemática e informática, como também desenvolve conhecimento sobre $\mathrm{o}$ ensino $\mathrm{e}$ aprendizado da matemática, física e informática nos territórios da maioria afrodescendente".

Oliveira (2011) recupera diversos conhecimentos matemáticos produzidos em África que podem ser utilizados tranquila e ludicamente em sala de aula para abordagem de diferentes conteúdos daquela disciplina; dentre eles, a autora destaca o Tsoro Yematatu, jogo de pedra jogado com três, que possibilita a construção de conceitos fundamentais para o prosseguimento, com sucesso, dos estudos escolares. É também Oliveira (2012b, p. 132) que sublinha que "como educadores $\mathrm{e}$ educadoras, reconhecendo-se ou não o racismo, reconhecendo-se ou não as africanidades presentes em nossa cultura, não se pode deixar, em hipótese 
alguma, que a discriminação ocupe os espaços escolares".

Gerdes (1997) resgata as variadas habilidades do povo quioco: "[...] famosos pela sua arte. Gostam de ornamentar as paredes das casas com desenhos. Fabricam esteiras e cestos decorados. Modelam cerâmica, esculpem madeira e forjam o ferro" (GERDES, 1997, p. 06) - trata-se de comunidade tradicional angolana. Este mesmo povo desenvolveu técnica de contação de história que recorre a conceitos matemáticos enquanto se faz desenhos na areia: para executar o desenho, o número necessário de linhas fechadas corresponde ao máximo divisor comum calculado a partir do número de filas e de colunas da rede de pontinhos e este cálculo é feito por crianças e adultos rapidamente e sem conhecimento daquele conteúdo da Matemática. Outro exemplo apresentado pelo mesmo pesquisador refere-se a estratégias de construção de moradias a partir da montagem de quadriláteros com ângulos retos:

Começa-se por estender no chão dois paus longos de bambu. Ambos os paus têm o comprimento igual ao comprimento desejado para a casa. Estes dois primeiros paus são então combinados com dois outros paus, também de igual comprimento, mas normalmente menores que os primeiros. Em seguida, movimenta-se os paus para formar um quadrilátero fechado. Por último, ajusta-se a figura até que as diagonais, medidas com uma corda - fiquem com igual comprimento. Onde ficam os paus estendidos no chão são então desenhadas linhas e a construção da casa pode começar (GERDES, 2010a, pp. 21-22).

Esta experiência de utilização espontânea da geometria representa uma construção axiomática alternativa ao quinto postulado de Euclides, conhecido como axioma das paralelas: "por um ponto fora de uma reta $m$ pode-se traçar uma única reta paralela à reta $m$ ". E conclui: "[...] ideias matemáticas não são alheias às culturas africanas, emerge-se uma consciência de que nem toda a Matemática vem da Europa [...]" (GERDES, 2010a, pp. 22-23).

Diversas outras experiências podem aqui ser enumeradas sem muita dificuldade, fazendo uso da Matemática e das demais disciplinas. Parece-nos oportuno trazer à baila o texto do professor Dagoberto José Fonseca, Vovó Nanã Vai à Escola.
Nele muitos conhecimentos produzidos por africanos, nas diferentes áreas, são mapeados - a consulta é aconselhável.

Há ainda três outros elementos que, em nosso olhar, devem integrar o currículo das unidades de ensino que oferecem a Educação Escolar Quilombola: Africanidades, Valores Civilizatórios Afro-Brasileiros e Territorialidade.

Para Lima e Trindade (2009, p. 17), africanidades podem ser concebidas como "repertórios culturais brasileiros que, em sua origem, dispositivos de base ou (re)elaboração históricas remetem ou se relacionam com as ancestralidades africanas". Trindade, ao passear pelos mundos, seus e do outro, e também pelos diálogos que eles travam e proporcionam, lembra que

Temos valores marcados por uma diversidade, somos descendentes de organizações humanas em processo constante de civilização - digo processo, e não evolução. Como afro-brasileiras e afrobrasileiros ciosas/os e orgulhosas/os desta condição, em diálogo com valores humanos de várias etnias e grupos sociais, imprimimos valores civilizatórios de matriz africana à nossa brasilidade que é plural (TRINDADE, 2010, p. 13).

No catálogo de valores civilizatórios afrobrasileiros, Trindade insere: 1) o Axé (energia vital); 2) a Circularidade (onde o Axé se movimenta); 3) a Corporeidade (materialização da energia vital); 4) a Memória (respeito aos saberes e fazeres já construídos); 5) a Ancestralidade (reconhecimento, valorização e respeito aos que vieram antes - e que se transformam em nossos protetores); 6) a Territorialidade; 7) a Religiosidade (território sagrado); 8) Cooperação e Comunitarismo; 9) a Oralidade (fundamental para a travessia, na e através das gerações, dos saberes construídos); 10) a Musicalidade; 11) a Ludicidade (o prazer de fazer, o prazer de dizer, o prazer de ser - o prazer de viver).

Quanto à territorialidade, além de compor a lista de valores civilizatórios afro-brasileiros, diz respeito ainda às formas como os quilombolas ocupam e utilizam a terra. Segundo O’Dwyer (2002, pp. 18-19), “a utilização dessas áreas obedece à sazonalização das atividades, sejam agrícolas, extrativistas ou outras, caracterizando diferentes formas de uso e ocupação dos elementos essenciais 
do ecossistema, que tomam por base laços de parentesco e vizinhança, assentados em relações de solidariedade e reciprocidade".

Africanidades, Valores Civilizatórios AfroBrasileiros e Territorialidade são saberes que se interpenetram e que penetram outros conhecimentos e valores que deverão compor os currículos das escolas quilombolas.

\section{Palavras finais}

A polifonia e polissemia do mundo, embora possam sofrer escalonamentos, permitem-nos entrar em contato com o diverso e com a diversidade. Torna-se preciso, contudo, que olhos e almas se abram, que se libertem de grilhões capazes de nos amarrar a preconceitos, discriminações e racismos e que nos impedem de enxergar - ou que apenas nos permitem olhar através de um véu denso, eclipsante, e que, por isso mesmo, dificulta a visão explícita, limpa daquilo que olhamos. Retirar este véu não é fácil, mesmo porque muitas vezes nem mesmo sabemos que o temos diante de nós, e que nossa visão está embaçada.

Talvez o melhor caminho para enxergar na diferença e no diferente outras possibilidades de ver e de trilhar o mundo seja aquele que, primeiro, desvela-nos. Ou seja, é preciso que nos conheçamos e reconheçamos nossos limites e possibilidades para transcendermos. N'outras palavras: se e quando aceitamos que não temos a propriedade da verdade, que ela não nos pertence, e que verdades outras que assumimos pública e aguerridamente foram, por nós mesmos/as, negadas, iniciamos um processo de humildade. Este processo é fulcral para que busquemos, no outro e com o outro, modos diferentes de ver, de fazer, de sentir e de viver.

É claro que há outros caminhos e outras formas de caminhar que também se fazem necessários para que ultrapassemos uma educação que mais exclui do que inclui e ingressemos em um território, mesmo em disputa, que reconheça a diferença e a diversidade como elementos potencializadores da ação pedagógica e das relações humanas; dentre eles, é possível citar: 1) a formação de professores/as, inicial e continuada; 2) a reconfiguração dos diálogos entre escola e contexto sociocultural; 3) a instituição efetiva da gestão democrática, em todos os âmbitos. Contudo, todas estas ações, e outras que podem ser incluídas, para serem efetivas, precisam da ressignificação do olhar e das relações entre as pessoas.

\section{Notas}

1 Lei sancionada em 09 de janeiro de 2003, que altera a Lei de Diretrizes e Bases da Educação Nacional, Lei no 9394/96, em seu artigo 26-A, tornando obrigatória a inclusão da História e Cultura Africana e Afro-brasileira nos currículos escolares da Educação Brasileira.

2 A referida Lei torna obrigatória a inclusão da História e Cultura Africana, Afro-brasileira e indígena nos currículos escolares.

3 Diretrizes Curriculares Nacionais para a Educação das Relações Étnico-Raciais e para o Ensino de História e Cultura Afro-Brasileira e Africana. Documento legal que orienta para o cumprimento da Lei ${ }^{\circ}$ 10.639/03.

\section{Referências}

ALMEIDA, Alfredo Wagner Berno de. Os quilombos e as novas etnias. In: O'DWYER, Eliane Cantarino. Quilombo: identidade étnica e territorialidade. Rio de Janeiro: Editora FGV, 2002.

ARRUTI, José Maurício Andion. Quilombos. In: Raça: Perspectiva Antropológica, 2008. Disponível em < http://pt.slideshare.net/FrancilisEnes/arrutijose-quilombos $>$. Acesso em 18 de junho de 2015.

BRASIL. Constituição Federal (1988). Brasília, 2007. Disponível em < http://www.planalto.gov.br/c civil_03/constituicao/constituicaocompilado.htm>.

Acesso em 23 de junho de 2015.

BRASIL. Decreto $N .^{\circ} 4.887$, de 20 de novembro de 2003. Disponível em < http://www.planalto.gov.br/c civil_03/decreto/2003/d4887.htm>. Acesso em 23 de junho de 2015.

BRASIL. Decreto $N .^{\circ} 6.040$, de 07 de fevereiro de 2007. Disponível em <http://www.planalto.gov.b r/ccivil_03/_ato2007-2010/2007/decreto/d6040.htm. Acesso em 23 de junho de 2015.

BRASIL. Diretrizes curriculares nacionais gerais da Educação Básica. MEC/SEB/SECADI, 2013.

BRASIL. Lei 10.639, de 9 de janeiro de 2003. Disponível em <http://www.planalto.gov.br/cc ivil_03/leis/2003/110.639.htm>. Acesso em 23 de junho de 2012. 
BRASIL. Lei 11.645, de 10 de março de 2008. Disponível em <http://www.planalto.gov.br/c civil_03/_ato2007-2010/2008/lei/111645.htm>.

Acesso em 23 de junho de 2012.

BRASIL. Lei de Diretrizes e Bases da Educação Nacional (LDBEN 9394/96). Brasília: MEC, 1997.

BRASIL. Programa Brasil Quilombola. Brasília: SEPPIR, 2004. Disponível em <http://www.sep pir.gov.br/publicacoes/brasilquilombola_2004.pdf>. Acesso em 23 de junho de 2015.

BRASIL. Resolução N. ${ }^{\circ}$ 01/2004, de 17 de junho de 2004. Disponível em <http://www.uel.br/projetos/le afro/pages/arquivos/DCN-s\%20-\%20Educacao\%20 das\%20Relac oes \%20 Etnico-Raciais.pdf>. Acesso em 23 de março de 2015.

BRASIL. Resolução CNE/CEB N. ${ }^{\circ}$ 08/2012, de 20 de novembro de 2012. Disponível em <http://www.seppir.gov.br/arquivos-pdf/diretrizes-c urriculares>. Acesso em 23 de junho de 2012.

BRASIL/CONSELHO NACIONAL DE EDUCAÇÃO. Parecer CNE/CEB N. ${ }^{\circ}$ 07/2010, aprovado em 07 de abril de 2010.

CHARLOT, Bernard. Relação com o Saber, Formação de Professores e Globalização questões para a educação hoje. Porto Alegre: Artmed, 2005.

CUNHA JÚNIOR, Henrique. Afroetnomatemática, África e Afrodescendência. In: CAVALCANTI, Bruno César et. al.(org.). Kulé-kulé: visibilidades negras. EDUFAL, 2006.

CUNHA JÚNIOR, Henrique. Tecnologia africana na formação brasileira. Rio de Janeiro: CEAP, 2010.

DOMINGUES, Petrônio. Movimento negro brasileiro: alguns apontamentos históricos. In: Tempo [online], vol.12, n.23, 2007. ISSN 14137704.

FONSECA, Dagoberto José. Vovó Nanã vai à escola. São Paulo: FTD, 2009.

FORQUIN, Jean-Claude. Escola e cultura: as bases sociais e epistemológicas do conhecimento escolar. Porto Alegre: Artes Médicas Sul, 1993.
FRANÇA, Evanilson Tavares de. Escola $e$ cotidiano: um estudo das percepções matemáticas da comunidade quilombola Mussuca em Sergipe. Universidade Federal de Sergipe, 2013.

FREIRE, Paulo. Pedagogia da Autonomia: saberes necessários à prática educativa. São Paulo: Paz e Terra, 2000.

GERDES, Paulus. Da Etnomatemática a artedesign e matrizes cíclicas. Belo Horizonte: Autêntica, 2010a.

GERDES, Paulus. Desenhos da África. São Paulo: Scipione, 1997.

GERDES, Paulus. Desenhos de Angola: viver a matemática. São Paulo: Editorial Diáspora, 2010b.

GONÇALVES, Luiz Alberto Oliveira; SILVA, Petronilha Beatriz Gonçalves e. Movimento negro e educação. In: Revista Brasileira de Educação. Set/Out/Nov/Dez 2000, No 15.

GILROY, Paul. $O$ Atlântico negro. São Paulo: Editora 34; Rio de Janeiro: Universidade Cândido Mendes, Centro de Estudos Afro-Asiáticos, 2012.

HALL, Stuart. A Identidade Cultural na Pósmodernidade. Rio de Janeiro : DP \&A, 2006.

LIBÂNEO, José Carlos. Didática. São Paulo: Cortez, 1994.

LIMA, Maria Batista; TRINDADE, Azoilda Loretto. Africanidades, Currículo e Formação Docente: desafios e possibilidades. In: MELO, Marcos Ribeiro de; LIMA, Maria Batista; LOPES, Edinéa Tavares. Identidades e Alteridades: debates e práticas a partir do cotidiano escolar. São Cristóvão/SE: UFS, 2009.

LOPES, Alice Casimiro; MACEDO, Elizabeth. Teorias de Currículo. São Paulo: Editora Cortez, 2011.

MACEDO, Roberto Sidnei. Atos de Currículo: uma incessante atividade etnometódica e fonte de análise de práticas curriculares. In: Currículo sem Fronteiras, v. 13, n. 3, p. 427-435, set./dez. 2013. Disponível em <http://www.curriculosemfronteir as.org/vol13iss3articles /macedo.pdf $>$. Acesso em 13 de março de 2015. 
MIRANDA, Shirley Aparecida de. Educação Escolar Quilombola em Minas Gerais: entre ausências e emergências. In: Revista Brasileira de Educação, v. 17, n. 50, maio-ago, 2012.

MUNANGA, Kabengele. Algumas considerações sobre "raça", ação afirmativa e identidade negra no Brasil: fundamentos antropológicos. In: Revista USP, São Paulo, n. 68, p. 46-57, dezembro/fevereiro, 2005-2006.

NIDELCOFF, María Teresa. Uma escola para o povo. São Paulo: Editora Brasiliense, 1985.

O'DWYER, Eliane Cantarino. Quilombo: identidade étnica e territorialidade. Rio de Janeiro: Editora FGV, 2002.

OLIVEIRA, Cristiane Coppe de. O programa Etnomatemática e o contexto étnico-racial na prática docente. In: XIII CIAEM-IACME, Recife, 2011. Disponível em <http://www.cimm.ucr.ac.cr/ocs/i ndex.php/xiii_cia em/xiii_ciaem/paper/viewFile/215 4/1207>. Acesso em 22 de março de 2012.

OLIVEIRA, Cristiane Coppe de. Saberes e fazeres etnomatemáticos de matriz africana. Rio de Janeiro: CEAP, 2012.

OLIVEIRA, Cristiane Coppe de. O Programa Etnomatemática e as possibilidades de implementação da Lei n. ${ }^{\circ}$ 10639/03. In:
BRANDÃO, Ana Paula (org.). Modos de fazer: caderno de atividades, saberes e fazeres. Rio de Janeiro: Fundação Roberto Marinho, 2010.

SACRISTÁN, J. Gimeno. O Currículo: uma reflexão sobre a prática. Porto Alegre: ArtMed, 2000.

SANTOS, Carlos. Território e territorialidade. In: Revista Zona de Impacto, ISSN 1982-9108, vol. 12, jul/dez, ano XI, 2009. Disponível em <http://www.albertolinscaldas.unir.br/TE RRIT\%C 3\%93RIO\%20E\%20TERRITORIALIDADE_vol12. html>. Acesso em 27 de junho de 2015.

SCHMITT, Alessandra; TURATTI, Maria Cecília Manzoli; CARVALHO, Maria Celina Pereira de. A atualização do conceito de quilombo: identidade e território nas definições teóricas. Ambient. soc. [online]. 2002, n.10, pp. 129-136. ISSN 1809-4422.

SILVA, Tomaz Tadeu da (org.). Documentos de Identidade: uma introdução às teorias de currículo. São Paulo: Autêntica, 2003.

TRINDADE, Azoilda Loretto. Valores civilizatórios afro-brasileiros e educação infantil: uma contribuição afro-brasileira. In: BRANDÃO, Ana Paula; TRINDADE, Azoilda Loretto (org.). Caderno de atividades saberes e fazeres. Rio de Janeiro: Fundação Roberto Marinho, 2010.

\section{Sobre os autores}

Evanilson Tavares de França é Mestre em Ensino de Ciências e Matemática pela UFS (NPGECIMA), pesquisador do Grupo de Estudos e Pesquisas Identidades e Alteridades: Diferenças e Desigualdades na Educação (GEPIADDE/UFS). Graduado em Pedagogia (Faculdade Pio Décimo). Atua como professor e pedagogo da Rede Estadual de Ensino (Secretaria de Estado da Educação/SEED - Sergipe).

Maria Batista Lima é Professora do Departamento de Educação do Campus Itabaiana (UFS) e do Núcleo de Pós-graduação em Ensino de Ciências e Matemática (NPGECIMA). Pesquisadora do Grupo de estudos e Pesquisas Identidades e Alteridades: Diferenças e Desigualdades na Educação (GEPIADE/UFS) e do Grupo de Pesquisa Educação e Contemporaneidade (EDUCON/UFS).

Recebido em maio de 2015.

Aprovado em setembro de 2015. 